\title{
The association between the FTO gene variant and alcohol consumption and binge and problem drinking in different gene- environment background: the HAPIEE study
}

Jaroslav A. Hubacek ${ }^{1}$, Hynek Pikhart ${ }^{2}$, Anne Peasey ${ }^{2}$, Sofia Malyutina ${ }^{3}$, Andrzej Pajak ${ }^{4}$, Abdonas Tamosiunas ${ }^{5}$, Mikhail Voevoda ${ }^{3}$, Michael V. Holmes ${ }^{6}$, Martin Bobak ${ }^{2}$

${ }^{1}$ Center for Experimental Medicine, Institute for Clinical and Experimental Medicine, Prague, Czech Republic

2International Institute for Health and Society, Department of Epidemiology and Public Health, University College London, UK

${ }^{3}$ Research Institute of Internal and Preventive Medicine - Branch of the Institute of Cytology and Genetics, SB RAS, Novosibirsk, Russia

${ }^{4}$ Department of Epidemiology and Population Studies, Institute of Public Health, Faculty of Health Care, Jagiellonian University Medical College, Krakow, Poland

${ }^{5}$ Department of Population Studies, Institute of Cardiology of Lithuanian University of Health Sciences, Kaunas, Lithuania

${ }^{6}$ National Institute for Health Research Oxford Biomedical Research Centre, Oxford University Hospital, Oxford, England

\section{Corresponding author:}

Jaroslav A. Hubacek

IKEM-CEM-LMG

Videnska 1958/9

14021 Prague 4

Czech Republic

Tel: +420 261363379

Fax: +420 241721574

E-mail: jahb@ikem.cz 


\section{Abstract}

BACKGROUND: Alcohol intake and tobacco smoking have significant negative health consequences and both are influenced by genetic predispositions. Some studies suggest that the FTO gene is associated with alcohol consumption. We investigated whether a tagging variant (rs17817449) within the FTO gene is associated with alcohol intake, problem drinking and smoking behaviour. METHODS: We analysed data from 26,792 Caucasian adults (47.2\% of males; mean age 58.9 ( \pm 7.3$)$ years), examined through the prospective cohort HAPIEE study. The primary outcomes were daily alcohol consumption, binge drinking, problem drinking (CAGE score 2+) and smoking status in relation to tagging variants within the FTO and $A D H 1 B$ genes. RESULTS: We found no significant association of the FTO polymorphism with smoking status in either sex. The associations of the FTO polymorphism with drinking pattern were inconsistent and differed by gender. In men, GG homozygote carriers had lower odds of problem drinking (OR $0.85,95 \% \mathrm{Cl} 0.75-0.96, \mathrm{p}=0.03$ ). In women, the combination of the FTO/ADH1B $\mathrm{GG} /+\mathrm{A}$ genotypes doubled the risk of binge drinking (OR 2.10, 95\% $\mathrm{Cl}$ 1.19-3.71, $\mathrm{p}<0.05)$, and the risk was further increased among smoking women $(\mathrm{OR} 4.10,95 \% \mathrm{Cl}$ 1.64-10.24, $\mathrm{p}=0.008)$. CONCLUSIONS: In this large population study, the FTO gene appeared associated with binge and problem drinking, and the associations were modified by sex, smoking status and the $A D H 1 B$ polymorphism.

\section{Key words}

FTO, polymorphism, alcohol intake, binge drinking, ADH1B, smoking, sex 


\section{Introduction}

Alcohol (chemically ethanol, $\mathrm{CH}_{3}-\mathrm{CH}_{2}-\mathrm{OH}$ ) consumed in the form of alcoholic beverages as well as tobacco smoking are listed among the avoidable risk factors that lead to enhanced mortality around the world. It is known that to some extent there is a heritable predisposition to both ethanol consumption and smoking. These predispositions are polygenic in character and comprise a list of genes with different variants and of relatively small, but still important and detectable influence, which contribute together to their determination (Corella 2012, Ware and Munafò 2015).

The pleiotropic effect of the tagging FTO ("fat mass and obesity-associated gene"; gene ID 79068, OMIM acc. No. 610966) variants within the first intron of the gene on human anthropometry, health and disease was recognised very quickly after FTO was detected as an important determinant of body weight (Dina et al., 2007, Frayling et al. 2007) and type 2 diabetes mellitus (Scott et al. 2007).

The exact mechanism of the FTO influence on disease development and anthropometrical changes remains in details unknown, it has been reported that the major function of FTO is to influence RNA (and also to a lesser extent DNA) methylation status (Gerken et al. 2007). Thus the effect of different FTO alleles may be mediated by epigenetic changes (Almén et al. 2012).

SNPs clustering in the first intron (generally, they are in a very strong linkage disequilibrium [Hubacek et al. 2009]) are not only associated with differences in BMI, but minor (but still very common, with allelic frequencies around $40 \%$ in Europeans) alleles of these variants increase the risk of a wide range of non-communicable diseases (Dina et al., 2007, Scott et al., 2007, Hubacek et al., 2012a, Hubacek et al., 2016, Keller et al., 2011, Huang et al., 2017). Among others, a possible association between FTO variants 
and the consumption of alcoholic beverages has been occasionally revealed in studies, but with controversial results (Sobczyk-Kopciol et al., 2011, Corella et al., 2012, Hubacek et al., 2012b, Nordestgaard et al., 2012).

However, there is a substantial lack of information concerning the association between the FTO polymorphism and alcohol consumption and smoking in large samples of the general population. To address this gap in the knowledge, we analysed the first intron tagging variant in almost 27,000 adult individuals from the Czech Republic, Russia, Lithuania and Poland. Further, since it is clear that the strongest determinant of ethanol intake is the common $A D H 1 B$ (rs1229984) polymorphism and that alcohol consumption (Hart and Kanzler 2015, Holmes et al., 2014, Oroszi and Goldman 2004) and smoking have been recently described as potential confounders for the association of the FTO polymorphism with drinking alcohol (Godyear et al. 2017), these two additional factors were included in the analysis.

\section{Materials and Methods}

All analyses were performed on adult individuals examined as part of the Health, Alcohol and Psychosocial Factors in Eastern Europe (HAPIEE) study. Subjects from population-based cohorts from the Czech Republic, Poland, Russia and Lithuania were included. The protocol of the examination was identical for all countries and is described in detail before (Peasey et al., 2006, Kumari et al., 2014).

Participant completed an extensive structured questionnaire under the supervision of a trained nurse, underwent a short objective examination in the clinic and provided a blood sample. Smoking status (never, past and current smoking) were assessed using a standard questions. Alcohol indices were derived from a detailed graduated frequency 
questionnaire (Rehm 1988) containing categories of frequency and amounts of ethanol consumed per single occasion (expressed in local units as $0.05 \mathrm{~L}$ of spirits, $0.2 \mathrm{~L}$ of wine and $0.5 \mathrm{~L}$ of beer) in the last 12 months. The total amount of alcohol consumed and the average alcohol intake were calculated from the amounts consumed and drinking frequency. Binge drinking was defined as drinking at least $100 \mathrm{~g}$ (males) or $60 \mathrm{~g}$ (females) of ethanol on one occasion at least once a month (for more details, see Pajak et al., 2013, Bobak et al., 2016). Problem drinking was defined as score of 2 or more on the CAGE questionnaire).

Covariates used in the analyses included age, sex, country, education (classified as primary, apprenticeship, secondary and university), marital status (married/cohabiting vs. single/widowed), economic activity (working, retired, unemployed, housewife) and number of household amenities (including car, TV, holidays possibilities).

The FTO gene variant rs17817449 was analysed using PCR-RFLP for the Czech part of the study population and using KASPTM technology (KBioscience, London, England) for the Russian, Lithuanian and Polish populations (Hubacek et al 2008 and 2011). A similar protocol (combination of PCR-RFLP and KASPTM technology) was used for analysing the $A D H 1 B$ rs1229984 genotype (Hubacek et al., 2012). Both different genotyping methods used are of a high accuracy and fully comparable (Hubacek et al. 2015).

Descriptive statistics (median and inter-quartile range) were calculated. Associations between genotype and binge and problem drinking were estimated by logistic regression. To increase the number of individuals in FTO genotype categories, carriers of TT and TG alleles were combined ( $T+$ category). Given the large differences in drinking patterns between men and women, analyses were stratified by sex. Two 
logistic regression models were fitted for each outcome in each gender; first, we adjusted for age and country, and second, we additionally adjusted for marital status, education, household amenities and socioeconomic status. Statistical analyses were performed using STATA 14 software.

\section{Results}

Population description

The descriptive characteristics of the examined individuals are summarised in Table 1. The total number of subjects with valid data on FTO (rs17817449) and ADH1B (rs1229984) genotypes and alcohol consumption indices and smoking was 26,792 subjects $(47.2 \%$ of males, aged $58.9 \pm 7.3$ years). The highest alcohol intake was observed in the Czech Republic. However, the highest prevalence of risky drinking patterns (both binge and problem drinking) were seen in Lithuanian subjects (Table 1).

Distribution of the FTO genotype in the combined sample is shown in Table 2. Across the full sample, $(p=0.16)$ and in both males $(p=0.17)$ and females $(p=0.53)$, and within each of the 4 populations, there was no evidence of deviation from the HardyWeinberg equilibrium. The distribution of the individual FTO genotypes was similar to neighbouring European countries (20\% of the population were homozygotes for the minor allele) and did not significantly differ between males and females $(p=0.25)$.

\section{Smoking and the FTO polymorphism}

We did not detect any associations between the FTO polymorphism and smoking behaviour. The frequencies of individual genotypes were almost identical among the groups of current smokers, past smokers and never smokers; both in males $(P=0.50)$ 
and females $(P=0.77)$ (not shown in tables). There were no significant association of smoking with the dominant (TT vs. + G allele carriers) or recessive (GG vs. + T allele carriers) models of the analysis.

\section{Alcohol consumption and the FTO polymorphism}

As there were significant differences between the self-reported amounts of ethanol consumption between males and females (males consumed about five times more alcohol than females), men and women were analysed separately. As noted in the methods, the recessive model (comparison of GG vs. T allele carriers) was deemed to be most effective for detecting the association between the FTO rs17817449 polymorphism and alcohol consumption indices. Therefore, all results were presented using this model.

We found no significant differences in weekly alcohol consumption between GG homozygotes and carriers of at least one $\mathrm{T}$ allele (Table 3 ) in either sex. Male GG homozygotes had lower prevalence of problem drinking but not binge drinking (Table 3). No associations were observed in females (Table 3). We further investigated the associations in multivariable logistic regression models. After controlling for age and country, the inverse association between GG allele and problem drinking in men persisted. Additional adjustment for socio-demographic variables did not change the estimates. We further controlled for body mass index and hypertension but the estimates remained unchanged (not shown). 


\section{Alcohol consumption on different gene-gene and gene-environment background}

On the background of the common $A D H 1 B$ GG genotype, we did not detect any statistically significant interactions between the FTO polymorphism, problem drinking or smoking status. After splitting the male and female subgroups according to the $A D H 1 B$ genotypes (GG homozygotes, consumers of more alcohol in the general population vs. A allele carriers), there appeared some sex-specific interaction. In females, the carriers of the combination of the $F T O / A D H 1 B \mathrm{GG} /+\mathrm{A}$ genotypes had double odds of binge drinking (OR 2.10, 95\% Cl 1.19-3.71) (Table 5). This odds was further doubled among current smokers, with OR of $4.10(1.64-10.24)$ (Table 6). However, given the small number of subjects in these post-hoc subgroup analyses, these results may well be false positive findings.

\section{Discussion}

In our large study based on homogenous groups of middle age individuals from 4 general populations, we did not detect a significant general association between FTO polymorphism and indices of alcohol intake, except of an inverse association problem drinking in males but not in females. In a subgroup analyses, a particular combination of FTO and $A D H 1 B$ polymorphisms with smoking status appeared to influence the risk of binge drinking in females but not in males. Given the small number of subjects in the sub-group analyses, the results need to be interpreted cautiously.

In the literature, only a few reports focus on FTO polymorphisms and alcohol consumption, with some supporting our finding that the association between the FTO polymorphism and alcohol consumption is of an inverse character, thus implying that the 
generally risky allele (associated, for example, with increased risk of T2DM, obesity, renal failure or myocardial infarction) is associated with lower alcohol consumption.

The first study on this topic (Sobczyk-Kopciol et al., 2011) detected an inverse association between the FTO rs9939609 polymorphism and alcohol consumption and the risk of alcoholism. Thus, the study concluded that the allele associated with higher BMI was protective against alcohol dependence. Using a SAGE sample, the minor $\mathrm{T}$ allele of rs8062891 (merged in fact into rs17817449) increases the risk of alcohol dependence (Wang et al., 2013), while additional rare (frequency below 5\%) alleles have also been associated with alcohol dependence. In a study by Corella et al. (2012), the authors reported a minor ( $\sim .5 \mathrm{~g} /$ day per variant/minor allele) but still significant decrease in alcohol consumption in carriers of the risky rs9939609 allele. No association between rs17817449 (which is almost in complete LD with rs9939609) and alcohol consumption or alcohol dependence has been detected in Czech populations (Hubacek et al., 2012), and also a large study of a Danish population found no association between rs9939609 and the number of alcoholic drinks consumed (Nordestgaard et al. 2012). Finally, a small study by Goodyear et al. (2017) described an interaction between the presence of the minor allele of the rs8050136 FTO SNP and smoking. Only smokers with this allele were at higher risk of alcohol dependence. Our study supports these results, albeit only in females and not in males.

The genetic influence of alcohol consumption and alcohol dependence is estimated at $50 \%$ (Corella 2012). However, the results from GWA studies clearly show that the genetic architecture that determines alcohol consumption is far more complex than in traits such as obesity or plasma lipids. In fact, as reviewed by Hart and Kranzler (2015), GWA studies are very inconsistent and barely detect some of the overlapping locuses 
and SNPs that are undoubtedly associated with alcohol consumption (with the exception of genes and coding proteins directly involved in alcohol metabolism, such as alcohol and aldehyde dehydrogenases). The variance of alcohol intake, influenced by SNPs only, has been estimated (using the SNP heritability and profile scoring methods) to be about $18 \%$ only (Vrieze et al. 2013).

According to GWA studies, the gene for FTO does not have a potential influence on alcohol consumption. This can be explained by the fact that the difference between the effects on alcohol consumption is, according to our results (this report and Hubacek et al. 2012), much lower ( $4 \mathrm{~g} /$ day vs $\sim 1 \mathrm{~g} /$ day) than the effects described for the rs1299884 SNP within the $A D H 1 B$ gene.

Although there have been several publications on the role of FTO regarding the genetic predisposition to smoking per se, they present conflicting results [SobczykKopcio et al., 2011, Bierut et al., 2007, Thorgeirsson et al. 2013, Hubacek et al., 2012, Wehby et al., 2016). Further, an overwhelming amount of publications report no association between FTO polymorphisms and smoking status or the number of cigarettes smoked per day. Also, GWA studies that have focused on the detection of smoking predisposition genes do not recognise FTO as a significant candidate.

Our study attempted to investigate gene-environment interactions but we faced the issue of the necessity of enrolling a large numbers of simultaneously phenotyped (lifestyle) and genotyped individuals. Although our study involved almost 27,000 subjects, the simple restriction of requiring female smokers and the further criterion that they be linked through two common SNPs led to the division of subgroups containing less than 500 subjects. 
Variants within the first intron of FTO are associated with many pleiotropic effects on human health. The association between the common FTO polymorphisms has been discussed in relation to the modulation of not only BMI values (obesity prevalence) (Dina et al., 2007, Frayling et al., 2007), but also of, for example, type 2 diabetes mellitus and their complications (Scott et al., 2007, Yang et al., 2017, Hubacek et al. 2018), cardiovascular disease (Hubacek et al., 2016), renal failure (Hubacek et al., 2012), total mortality (Zimmermann et al. 2009), abortion (Andraweera et al., 2015, Hubacek et al. 2016), Alzheimer's disease (Keller et al., 2011, Reitz et al., 2012), dementia (Keller et al., 2011) and some types of cancer (Huang et al., 2017, Hernández-Caballero and Sierra-Ramírez 2015).

To make the straightforward associations more complicated, the alleles associated with increased risk of the above-mentioned non-communicable diseases are inversely associated with suicide (Chojnicka et al., 2014), lower brain volume (Melka et al., 2013) and papillary thyroid cancer (Zhao et al., 2016).

The possible mechanism by which FTO influences health status is still not completely clear, but it could be mediated by different epigenetic factors, such as RNA and DNA demethylation, the influence of some miRNA concentrations or an effect on relative telomere length (Gerken et al., 2007, Almén et al., 2012, Berulava et al., 2015, Dlouha et al., 2012, Jia et al., 2011, Fu and He et al., 2012). Moreover, alcohol intake/alcoholism may have a significant epigenetic background, while FTO could be a mediator between genes and the environment. In fact, it has been reported that a list of genes putatively associated with alcoholism are differentially methylated (both hypo- and hyper-methylations have been described) (Nieratschker et al., 2013). 
The limitations of our study are similar to the same obstacles seen in other studies that focus on the analysis of ethanol consumption. Firstly, self-reported information on the consumption of alcoholic beverages is prone to under-reporting and misclassification. This under-reporting is more pronounced in females than in males, since in females ethanol consumption is socially stigmatised, as evidenced by Czech post-MONICA females, of which group unreallistic roughly two thirds self-reported to be abstainers [Adamkova, personal communication]. On the other hand, risky drinking patterns such as binge drinking seem to be less under-reported than regular ethanol intake (Phillips and Davey Smith 1991). A major limitation is the small sample size in the subgroup analyses. It is well possible that the interactive effects may simply be a falls positive finding. Finally, in the absence of GWAS genotyping, we were unable to adjust for principal components, meaning that there is a risk of confounding by population stratification. However, when we compared the allele frequencies of the two SNPs across geographical regions, they were broadly similar. Furthermore, the association of the genetic variants with alcohol consumption and adiposity was also similar across geographical regions. Collectively, these findings argue against major confounding arising from population stratification.

Despite these issues, our study had several strengths. Our data on alcohol intake strongly correlates with the measures obtained through food frequency questionnaires and repeated assessments of alcohol intake (Bobak et al., 2016). These validate the presented results. Further, all examined subjects were selected and examined according to an identical protocol. The study included older subjects (at least 45 years old); this group has been less well studied in terms of drinking pattern, perhaps because 
there are fewer binge drinkers in the elderly compared with younger age groups (Farke and Anderson 2007).

In our study, the allele which has been thus far described negatively and which is associated with increased risk of many diseases was associated with less risky drinking behaviours. However, under some environmental circumstances it was also associated with problem drinking. Interestingly, the genotype associated with increased alcohol consumption in males seems to be protective against binge drinking in some subgroups of females. These inconsistent finding are difficult to explain and they should be considered with cautious, at least until they are successfully replicated.

Our results suggest further possible FTO gene-environment interactions, such as those between FTO, depression and BMI values (Rivera et al., 2017) as well as common interactions between FTO variants and reduced physical activity, high caloric diets and BMI values (Kalantari et al., 2016, Livingstone et al., 2015).

Our results inversely associating the minor FTO allele with lower alcohol intake are in indirect agreement with the Mendelian randomisation study (Holmes et al., 2014), which concluded against expectations (using $A D H 1 B$ rs1229984 SNP as an instrument) that increased alcohol intake is not protective against CVD.

We conclude, that the FTO variability could, under some circumstances, influence the alcohol consumption habits and our results underline the necessity of complex analyses, taking into account multiple genes and different environmental backgrounds. 


\section{Acknowledgements}

We thank the patients and controls for their participation in the study.

The study was supported by the MH CZ-DRO („Institute for Clinical and Experimental Medicine - IKEM, IN 00023001“); by the Welcome Trust, the US National Institute of Aging and project no. RCSF 14-45-00030-П (Russian Federation).

\section{Disclosures}

All authors declare that they have no conflict of interest. 


\section{References}

1. Corella D (2012) Alcohol intake. Prog Mol Biol Transl Sci 108:261-292.

2. Ware JJ, Munafò MR (2015) Genetics of smoking behaviour. Curr Top Behav Neurosci 23:19-36.

3. Dina C, Meyre D, Gallina S, Durand E, Körner A, Jacobson P, Carlsson LM, Kiess W, Vatin V, Lecoeur C, Delplanque J, Vaillant E, Pattou F, Ruiz J, Weill J, LevyMarchal C, Horber F, Potoczna N, Hercberg S, Le Stunff C, Bougnères P, Kovacs P, Marre M, Balkau B, Cauchi S, Chèvre JC, Froguel P (2007) Variation in FTO contributes to childhood obesity and severe adult obesity. Nat Genet 39:724-726.

4. Frayling T.M., Timpson N.J., Weedon M.N., Zeggini E., Freathy R.M., Lindgren C.M. et al. A common variant in the FTO gene is associated with body mass index and predisposes to childhood and adult obesity. Science 2007; 316: 889-94.

5. Scott L.J., Mohlke K.L., Bonnycastle L.L., Willer C.J., Li Y., Duren W.L. et al. A genome-wide association study of type 2 diabetes in Finns detects multiple susceptibility variants. Science 2007; 316: 1341-5.

6. Gerken T., Girard C.A., Tung Y.C., Webby C.J., Saudek V., Hewitson K.S. et al. The obesity-associated FTO gene encodes a 2-oxoglutarate-dependent nucleic acid demetylase. Science 2007; 318: 1469-72.

7. Almén M.S., Jacobsson J.A., Moschonis G., Benedict C., Chrousos G.P., Fredriksson R. et al. Genome wide analysis reveals association of a FTO gene variant with epigenetic changes. Genomics 2012; 99: 132-7.

8. Hubacek J.A., Pitha J., Adamkova V., Lanska V., Poledne R. A common variant in the FTO gene is associated with body mass index in males and postmenopausal 
females but not in premenopausal females. Czech post-MONICA and 3PMFs studies. Clin Chem Lab Med 2009; 47: 387-90.

9. Hubacek J.A., Viklicky O., Dlouha D., Bloudickova S., Kubinova R., Peasey A. et al. The FTO gene polymorphism is associated with end-stage renal disease: two large independent case-control studies in a general population. Nephrol Dial Transplant 2012; 27: 1030-5.

10. Hubacek J.A., Vrablik M., Dlouha D., Stanek V., Gebauerova M., Adamkova V. et al. Gene variants at FTO, 9p21, and $2 q 36.3$ are age-independently associated with myocardial infarction in Czech men. Clin Chim Acta 2016; 454: 119-23.

11. Keller L., Xu W., Wang H.X., Winblad B., Fratiglioni L., Graff C. The obesity related gene, FTO, interacts with APOE, and is associated with Alzheimer's disease risk: a prospective cohort study. J Alzheimers Dis 2011; 23: 461-9.

12. Huang X., Zhao J., Yang M., Li M., Zheng J. Association between FTO gene polymorphism (rs9939609 T/A) and cancer risk: a meta-analysis. Eur J Cancer Care (Engl) 2017; 26(5).

13. Sobczyk-Kopciol A., Broda G., Wojnar M., Kurjata P., Jakubczyk A., Klimkiewicz A. et al. Inverse association of the obesity predisposing FTO rs9939609 genotype with alcohol consumption and risk for alcohol dependence. Addiction 2011; 106: 739-48.

14. Corella D., Ortega-Azorín C., Sorlí J.V., Covas M.I., Carrasco P., Salas-Salvadó J. et al. Statistical and biological gene-lifestyle interactions of MC4R and FTO with diet and physical activity on obesity: new effects on alcohol consumption. PLOS One 2012; 7: e52344. 
15. Hubacek J.A., Adamkova V., Dlouha D., Jirsa M., Šperl J., Tönjes A. et al. Fat mass and obesity-associated (fto) gene and alcohol intake. Addiction 2012; 107: 1185-6.

16. Nordestgaard B.G., Palmer T.M., Benn M., Zacho J., Tybjaerg-Hansen A., Davey Smith G. et al. The effect of elevated body mass index on ischemic heart disease risk: causal estimates from a Mendelian randomization approach. PLoS Med 2012; 9: e1001212.

17. Hart A.B., Kranzler H.R. Alcohol dependence genetics: Lessons learned from genome-wide association studies (GWAS) and post-GWAS analyses. Alcohol Clin Exp Res 2015; 39: 1312-27.

18. Holmes M.V., Dale C.E., Zuccolo L., Silverwood R.J., Guo Y., Ye Z. et al. Association between alcohol and cardiovascular disease: Mendelian randomisation analysis based on individual participant data. BMJ 2014; 349: g4164.

19. Oroszi G., Goldman D. Alcoholism: genes and mechanisms. Pharmacogenomics 2004; 5: 1037-48.

20. Goodyear K., Lee M.R., Schwandt M.L., Hodgkinson C.A., Leggio L. Hepatic, lipid and genetic factors associated with obesity: crosstalk with alcohol dependence? World J Biol Psychiatry 2017; 18: 120-8.

21. Peasey A., Bobak M., Kubinova R., Malyutina S., Pajak A., Tamosiunas A. et al. Determinants of cardiovascular disease and other non-communicable diseases in Central and Eastern Europe: rationale and design of the HAPIEE study. BMC Public Health 2006; 6: 255. 
22. Kumari M., Holmes M.V., Dale C.E., Hubacek J.A., Palmer T.M., Pikhart H. et al. Alcohol consumption and cognitive performance: a Mendelian randomization study. Addiction 2014; 109: 1462-71.

23. Rehm J. Measuring quantity, frequency and volume of drinking. Alcohol Clin Exp Res 1988; 22 Suppl: 4S-14S.

24. Pajak A., Szafraniec K., Kubinova R., Malyutina S., Peasey A., Pikhart H. et al. Binge drinking and blood pressure: cross-sectional results of the HAPIEE study. PLoS One 2013; 8: e65865.

25. Bobak M., Malyutina S., Horvat P., Pajak A., Tamosiunas A., Kubinova R. et al. Alcohol, drinking pattern and all-cause, cardiovascular and alcohol-related mortality in Eastern Europe. Eur J Epidemiol 2016; 31: 21-30.

26. Hubacek J.A., Pikhart H., Pesey A., Kubinova R., Bobak M. FTO variant, energy intake, physical activity and basal metabolit rate in caucasians. The HAPIEE study. Physiol Res 2011; 60: 175-83.

27. Hubacek J.A., Bohuslavova R., Kuthanova L., Kubinova R., Peasey A., Pikhart H. et al. The FTO gene and obesity in a large Eastern European population sample: the HAPIEE study. Obesity (Silver Spring) 2008; 16: 2764-6.

28. Hubacek J.A., Pikhart H., Peasey A., Kubinova R., Bobak M. ADH1B polymorphism, alcohol consumption, and binge drinking in Slavic Caucasians: results from the Czech HAPIEE study. Alcohol Clin Exp Res 2012; 36: 900-5.

29. Hubáček J.A., Pikhart H., Peasey A., Kubínová R., Bobák M. Nobody is perfect: Comparison of the accuracy of PCR-RFLP and KASPTM method for genotyping. ADH1B and FTO polymorphisms as examples. Folia Biol (Praha). 2015; 61: 15660. 
30. Wang L., Liu X., Luo X., Zeng M., Zuo L., Wang K.S. Genetic variants in the fat mass- and obesity-associated (FTO) gene are associated with alcohol dependence. J Mol Neurosci 2013; 51: 416-24.

31. Vrieze S.I., McGue M., Miller M.B., Hicks B.M., lacono W.G. Three mutually informative ways to understand the genetic relationships among behavioral disinhibition, alcohol use, drug use, nicotine use/dependence, and their cooccurrence: twin biometry, GCTA, and genome-wide scoring. Behav Genet 2013; 43: $97-107$.

32. Bierut L.J., Madden P.A., Breslau N., Johnson E.O., Hatsukami D., Pomerleau O.F. et al. Novel genes identified in a high-density genome wide association study for nicotine dependence. Hum Mol Genet 2007; 16: 24-35.

33. Thorgeirsson T.E., Gudbjartsson D.F., Sulm P., Besenbacher S., Styrkarsdottir U., Thorleifson G. et al. A common biological basis of obesity and nicotine addiction. Transl Psychiatry 2013; 3: e308.

34. Hubacek J.A., Dlouha D., Lanska V., Adamkova V. Lack of an association between three tagging SNPs within the FTO gene and smoking behavior. Nicotine Tob Res 2012; 14: 998-1002.

35. Wehby C.L., Prater K.N., Ryckman K.K., Kummet C., Murray J.C. Candidate gene study for smoking, alcohol use, and body weight in a sample of pregnant women. $J$ Matern Fetal Neonatal Med 2016; 28: 804-11.

36. Yang Y., Liu B., Xia W., Yan J., Liu H.Y., Hu L. et al. FTO genotype and type 2 diabetes mellitus: Spatial analysis and meta-analysis of 62 case-control studies from different regions. Genes (Basel) 2017; 8(2). 
37. Hubacek J.A., Dlouha D., Klementova M., Lanska V., Neskudla T., Pelikanova T. The FTO variant is associated with chronic complications of diabetes mellitus in Czech population. Gene 2018; 642: 220-4.

38. Zimmermann E., Kring S.I., Berentzen T.L., Holst C., Pers T.H., Hansen T. et al. Fatness-associated FTO gene variant increases mortality independent of fatness in cohorts of Danish men. PLoS One 2009; 4: e4428.

39. Andraweera P.H., Dekker G.A., Jayasekara R.W., Dissanayake V.H., Roberts C.T. The obesity-related FTO gene variant associates with the risk of recurrent miscarriage. Acta Obstet Gynecol Scand 2015; 94: 722-6.

40. Hubacek J.A., Kasparova D., Dlouha D., Pikhart H., Bobak M., Fait T. FTO gene variant and risk of spontaneous abortion. Acta Obstet Gynecol Scand 2016; 95: 118.

41. Reitz C., Tosto G., Mayeux R., Luchsinger J.A.; NIA-LOAD/NCRAD Family Study Group; Alzheimer's Disease Neuroimaging Initiative. Genetic variants in the Fat and Obesity Associated (FTO) gene and risk of Alzheimer's disease. PLoS One 2012; 7: e50354.

42. Hernández-Caballero M.E., Sierra-Ramírez J.A. Single nucleotide polymorphisms of the FTO gene and cancer risk: an overview. Mol Biol Rep 2015; 42: 699-704.

43. Chojnicka I., Fudalej S., Walczak A., Wasilewska K., Fudalej M., Stawiński P. et al. Inverse association between obesity predisposing FTO genotype and completed suicide. PLoS One 2014; 9: e108900.

44. Melka M.G., Gillis J., Bernard M., Abrahamowicz M., Chakravarty M.M., Leonard G.T. et al. FTO, obesity and the adolescent brain. Hum Mol Genet 2013; 22: 10508. 
45. Zhao J., Huang X., Yang M., Li M., Zheng J. Association between the FTO rs8050136 polymorphism and cancer risk: a meta-analysis. Fam Cancer 2016; 15: $145-53$

46. Berulava T., Rahmann S., Rademacher K., Klein-Hitpass L., Horsthemke B. N6adenosine methlaion in miRNAs. PLoS One 2015; 10: e0118438.

47. Dlouha D., Pitha J., Lanska V., Hubacek J.A. Association between FTO 1st intron tagging variant and telomere length in middle aged females. 3PMFs study. Clin Chim Acta 2012; 413: 1222-25.

48. Jia G., Fu Y., Zhao X., Dai Q., Zheng G., Yang Y. et al. N6-methyladenosine in nuclear RNA is a major substrate of the obesity-associated FTO. Nat Chem Biol $2011 ; 7: 885-7$.

49. Fu Y., He C. Nucleic acid modifications with epigenetic significance. Curr Opin Chem Biol. 2012; 16: 516-24.

50. Nieratschker V., Batra A, Fallgatter AJ. Genetic and epigenetic of alcohol dependence. J Mol Psychiatry 2013; 1: 11.

51. Phillips A.N., Davey Smith G. How independent are "independent" effects? Relative risk estimation when correlated exposures are measured imprecisely. J Clin Epidemiol 1991; 44: 1223-31.

52. Farke W., Anderson P. Binge drinking in Europe. Adicciones 2007; 19: 333-9.

53. Rivera M., Locke A.E., Corre T., Czamara D., Wolf C., Ching-Lopez A. et al. Interaction between the FTO gene, body mass index and depression: metaanalysis of 13701 individuals. Br J Psychiatry 2017; 212: 70-6.

54. Kalantari N., Doaei S., Keshavarz-Mohammadi N., Gholamalizadeh M., Pazan N. Review of studies on the fat mass and obesity-associated (FTO) gene interactions 
with environmental factors affecting on obesity and its impact on lifestyle interventions. ARYA Atheroscler 2016; 12: 281-90.

55. Livingstone K.M., Celis-Morales C., Lara J., Ashor A.W., Lovegrove J.A., Martinez J.A. et al. Associations between FTO genotype and total energy and macronutrient intake in adults: a systematic review and meta-analysis. Obes Rev 2015; 16: 66678. 
Table 1 Descriptive statistics of the subjects studied.

\begin{tabular}{lccccc}
\hline \multicolumn{1}{c}{ Country } & Czech Rep. & Lithuania & Poland & Russia & Total \\
\hline $\mathrm{N}$ & 6182 & 6738 & 6897 & 6975 & 26792 \\
Males (\%) & 46.5 & 45.7 & 53.5 & 42.9 & 47.2 \\
Age, years, mean \pm SD & $58.2 \pm 7.1$ & $61.0 \pm 7.6$ & $57.4 \pm 7.0$ & $58.8 \pm 7.1$ & $58.9 \pm 7.3$ \\
Weekly alcohol intake (g), & $43(0-150)$ & $18(0-50)$ & $8(0-80)$ & $10(0-20)$ & $5(0-74)$ \\
median (inter-quartile range) & & & & 26.5 & 28.6 \\
Current smoking (\%) & 25.5 & 19.0 & 30.0 & 8.5 & 8.2 \\
Problem drinking (\%) & 5.6 & 12.5 & 5.9 & 8.4 & 16.3 \\
Binge drinking (\%) & 14.2 & 17.1 & & & \\
\end{tabular}

* Median (inter-quartile range)

* Binge drinking: $\geq 100 \mathrm{~g}$ (men) or $\geq 60 \mathrm{~g}$ (women) of ethanol at single occasion at least once a month in the past year.

** Problem drinking: CAGE score $\geq 2$ 
Table 2. Distribution of the FTO genotype (all countries combined).

\begin{tabular}{lccc}
\hline FTO genotype & Total, n (\%) & Males, n (\%) & Females, n (\%) \\
\hline GG & $5305(19.8)$ & $2560(20.1)$ & $2745(19.5)$ \\
GT & $13101(48.9)$ & $6212(48.8)$ & $6889(49.0)$ \\
TT & $8386(31.3)$ & $3959(31.1)$ & $4427(31.5)$ \\
HW equilibrium (p-value) & 0.16 & 0.17 & 0.53 \\
\hline
\end{tabular}


Table 3 Median (inter-quartile range) of weekly alcohol intake $(\mathrm{g})$ and prevalence of binge drinking and problem drinking by FTO genotype in males and females (drinkers only) in crude analyses.

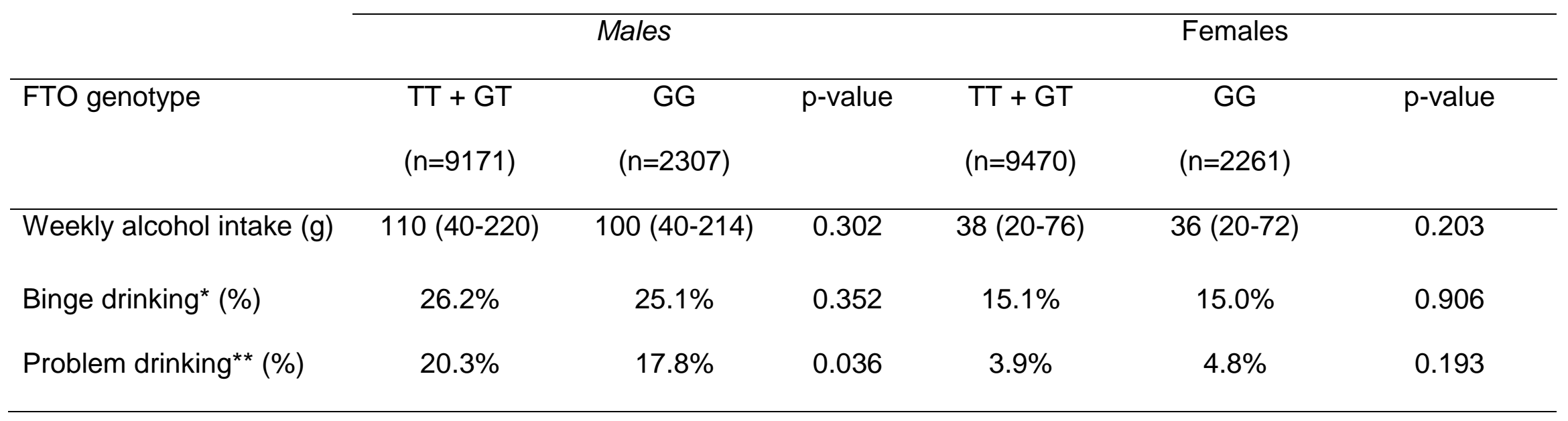

* Binge drinking: $\geq 100 \mathrm{~g}$ (men) or $\geq 60 \mathrm{~g}$ (women) of ethanol at single occasion at least once a month in the past year.

** Problem drinking: CAGE score $\geq 2$ 
Table 5. Odds ratios of binge drinking and problem drinking by the $F T O$ and $A D H 1 B$ genotypes, separately in males and females.

\begin{tabular}{|c|c|c|c|c|c|c|}
\hline & \multicolumn{3}{|c|}{ Males } & \multicolumn{3}{|c|}{ Females } \\
\hline & $\mathrm{N}$ & OR $(95 \% \mathrm{Cl})^{1}$ & OR $(95 \% \mathrm{Cl})^{2}$ & $\mathrm{~N}$ & OR $(95 \% \mathrm{Cl})^{1}$ & OR $(95 \% \mathrm{Cl})^{2}$ \\
\hline \multicolumn{7}{|l|}{ Binge drinking } \\
\hline$+\mathrm{T}(\mathrm{FTO}) /+\mathrm{A}(\mathrm{ADH} 1 \mathrm{~B})$ & 978 & 1.00 & 1.00 & 1067 & 1.00 & 1.00 \\
\hline GG (FTO) / GG (ADH1B) & 2278 & $0.93(0.83-1.04)$ & $0.94(0.84-1.06)$ & 2475 & $0.88(0.74-1.06)$ & $0.89(0.75-1.06)$ \\
\hline GG (FTO) / +A (ADH1B) & 248 & $1.13(0.79-1.62)$ & $1.08(0.75-1.55)$ & 246 & $2.10(1.21-3.65)^{*}$ & $2.10(1.19-3.71)^{\star}$ \\
\hline \multicolumn{7}{|l|}{ CAGE 2+ } \\
\hline$+\mathrm{T}(\mathrm{FTO}) /+\mathrm{A}(\mathrm{ADH} 1 \mathrm{~B})$ & 978 & 1.00 & 1.00 & 1067 & 1.00 & 1.00 \\
\hline GG (FTO) / GG (ADH1B) & 2278 & $0.85(0.74-0.97)$ & $0.85(0.75-0.98)$ & 2475 & $0.97(0.70-1.33)$ & $0.97(0.70-1.34)$ \\
\hline GG (FTO) / +A (ADH1B) & 248 & $0.85(0.54-1.35)$ & $0.82(0.52-1.30)$ & 246 & $1.80(0.57-5.75)$ & $1.67(0.50-5.42)$ \\
\hline
\end{tabular}

Binge drinking: $\geq 100 \mathrm{~g}$ (men) or $\geq 60 \mathrm{~g}$ (women) of ethanol at single occasion at least once a month in the past year.

Problem drinking: CAGE score $\geq 2$

1 adjusted for age and country

2 adjusted for age, country, marital status, education, economic status and household amenities.

* $P<0,05$ 
Table 6 Risk of binge drinking in females by FTO gene in ADH1B A allele carriers according to different smoking status backgrounds.

\begin{tabular}{llll}
\hline & FTO genotype & \multicolumn{1}{c}{ OR $(95 \% \mathrm{Cl})^{1}$} & OR $(95 \% \mathrm{Cl})^{2}$ \\
\hline Never smokers & $+\mathrm{T}$ & 1.00 & 1.00 \\
$(\mathrm{n}=850)$ & $\mathrm{GG}$ & $1.14(0.42-3.10)$ & $1.14(0.41-3.20)$ \\
& & & \\
Past smokers & $+\mathrm{T}$ & 1.00 & 1.00 \\
$(\mathrm{n}=240)$ & $\mathrm{GG}$ & $2.31(0.52-10.34)$ & $3.16(0.53-18.84)$ \\
& & & 1.00 \\
Current smokers & $+\mathrm{T}$ & 1.00 & $4.10(1.64-10.24) \S$ \\
$(\mathrm{n}=189)$ & $\mathrm{GG}$ & $3.54(1.54-8.15) \S$ & \\
\hline
\end{tabular}

\section{${ }^{1}$ adjusted for age and country}

2 adjusted for age, country, marital status, education, economic status and household amenities.

$\S P<0.008$ 